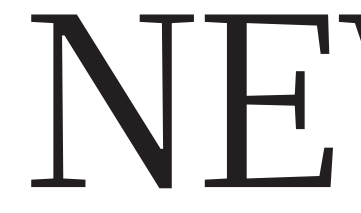

ARSENIC Scientists seek the source of contaminated groundwater $\mathbf{p . 4 3 7}$

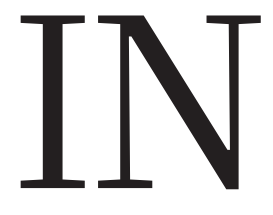

GLOBAL hEALTH Researchers raise questions over malaria vaccine $\mathbf{p . 4 3 9}$
STEM CELLS The bright side of Europe's lamented patent ruling $\mathbf{p . 4 4 1}$
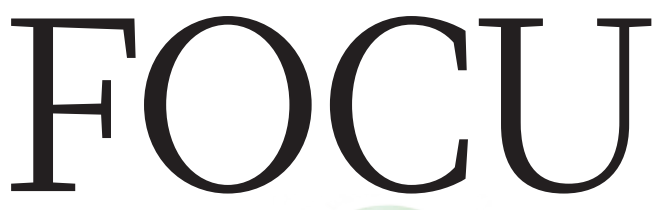

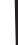

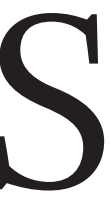

NEUROSCIENCE The

shortage of children's brains in research $\mathbf{p . 4 4 2}$

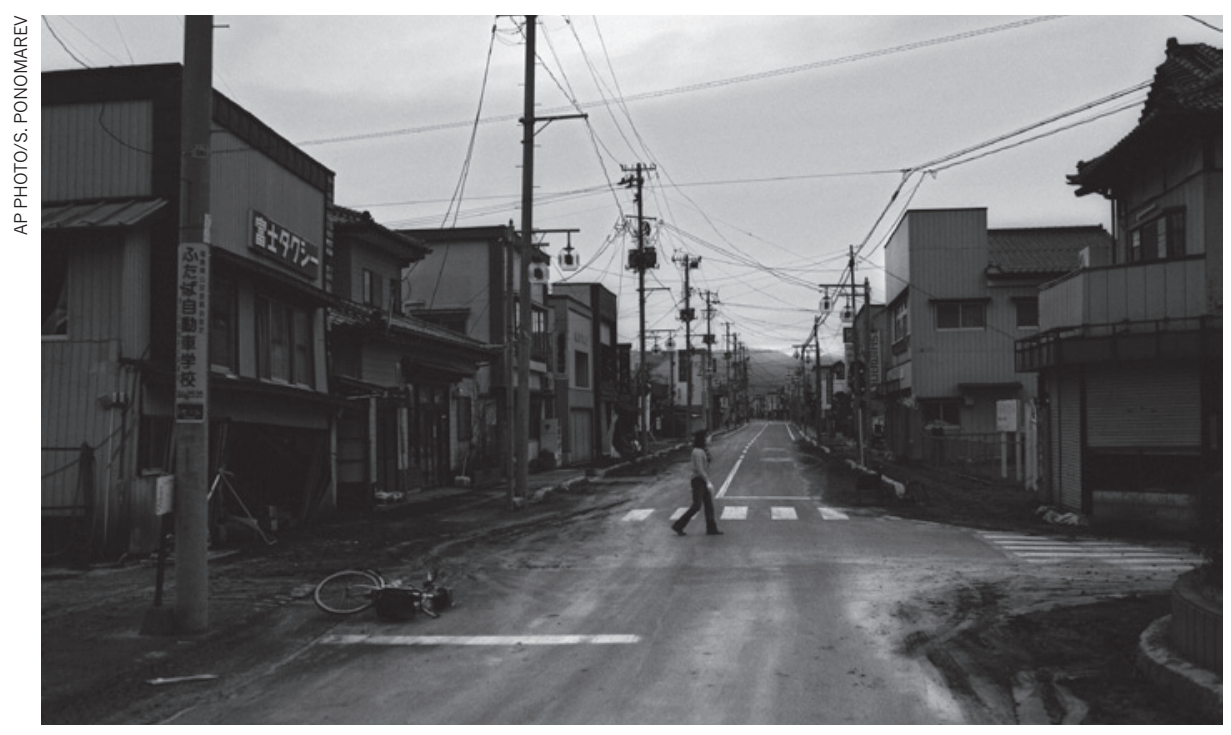

The Fukushima accident led to mass evacuations from nearby towns such as Minamisoma.

\title{
NUCLEAR DISASTER
}

\section{Fallout forensics hike radiation toll}

\section{Global data on Fukushima challenge Japanese estimates.}

\section{BY GEOFF BRUMFIEL}

$\mathrm{T}$ The disaster at the Fukushima Daiichi nuclear plant in March released far more radiation than the Japanese government has claimed. So concludes a study that combines radioactivity data from across the globe to estimate the scale and fate of emissions from the shattered plant.

The study also suggests that, contrary to government claims, pools used to store spent nuclear fuel played a significant part in the release of the long-lived environmental contaminant caesium-137, which could have been prevented by prompt action. The analysis has been posted online for open peer review by the journal Atmospheric Chemistry and Physics.

Andreas Stohl, an atmospheric scientist with the Norwegian Institute for Air Research in Kjeller, who led the research, believes that the analysis is the most comprehensive effort yet to understand how much radiation was released from Fukushima Daiichi. "It's a very valuable contribution," says Lars-Erik De Geer, an atmospheric modeller with the Swedish Defense Research Agency in Stockholm, who was not involved with the study.

The reconstruction relies on data from dozens of radiation monitoring stations in Japan and around the world. Many are part of a global network to watch for tests of nuclear weapons that is run by the Comprehensive NuclearTest-Ban Treaty Organization in Vienna. The scientists added data from independent stations in Canada, Japan and Europe, and then combined those with large European and American caches of global meteorological data.

Stohl cautions that the resulting model is far from perfect. Measurements were scarce in the immediate aftermath of the Fukushima accident, and some monitoring posts were too contaminated by radioactivity to provide reliable data. More importantly, exactly what happened inside the reactors - a crucial part of understanding what they emitted — remains a mystery that may never be solved. "If you look at the estimates for Chernobyl, you still have a large uncertainty 25 years later," says Stohl.

Nevertheless, the study provides a sweeping view of the accident. "They really took a global view and used all the data available," says De Geer.

\section{CHALLENGING NUMBERS}

Japanese investigators had already developed a detailed timeline of events following the 11 March earthquake that precipitated the disaster. Hours after the quake rocked the six reactors at Fukushima Daiichi, the tsunami arrived, knocking out crucial diesel back-up generators designed to cool the reactors in an emergency. Within days, the three reactors operating at the time of the accident overheated and released hydrogen gas, leading to massive explosions. Radioactive fuel recently removed from a fourth reactor was being held in a storage pool at the time of the quake, and on 14 March the pool overheated, possibly sparking fires in the building over the next few days.

But accounting for the radiation that came from the plants has proved much harder than reconstructing this chain of events. The latest report from the Japanese government, published in June, says that the plant released $1.5 \times 10^{16}$ bequerels of caesium-137, an isotope with a 30-year half-life that is responsible for most of the long-term contamination from the plant ${ }^{2}$. A far larger amount of xenon-133, $1.1 \times 10^{19} \mathrm{~Bq}$, was released, according to official government estimates.

The new study challenges those numbers. On the basis of its reconstructions, the team claims that the accident released around $1.7 \times 10^{19} \mathrm{~Bq}$ of xenon-133, greater than the estimated total radioactive release of $1.4 \times 10^{19} \mathrm{~Bq}$ from Cher-

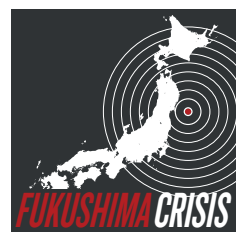

$\rightarrow$ WWW.NATURE. COM/JAPANQUAKE nobyl. The fact that three reactors exploded in the Fukushima accident accounts for the huge xenon tally, says De Geer. Xenon-133 does not pose serious health risks because it is not absorbed by the body 


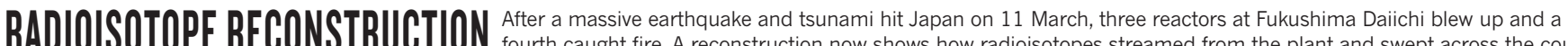

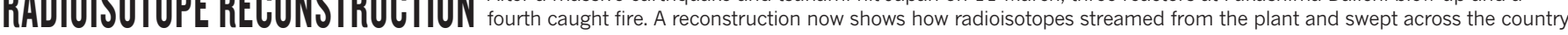
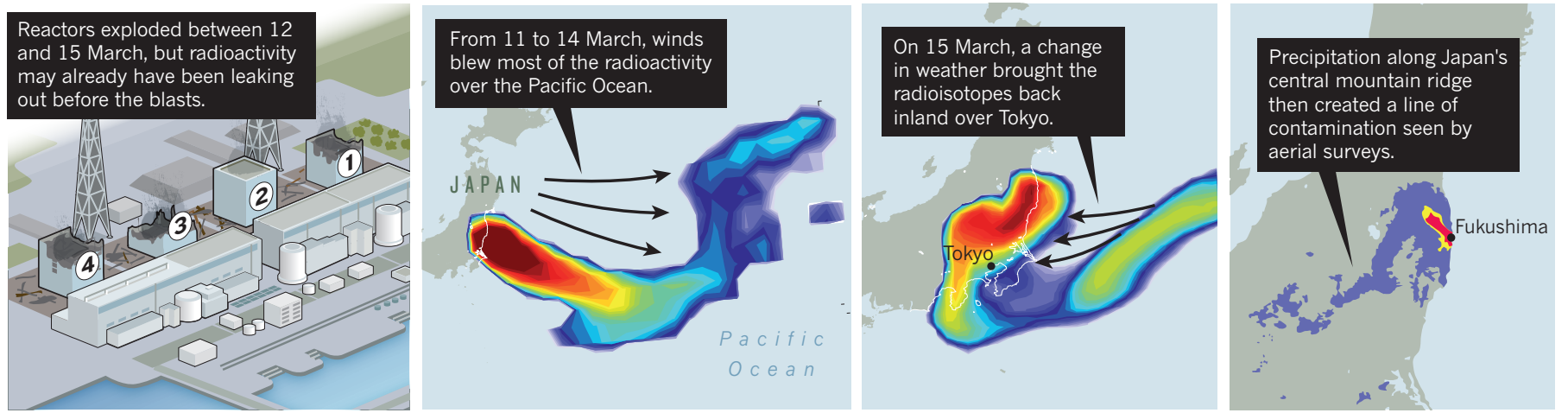

or the environment. Caesium-137 fallout, however, is a much greater concern because it will linger in the environment for decades. The new model shows that Fukushima released $3.5 \times 10^{16} \mathrm{~Bq}$ caesium-137, roughly twice the official government figure, and half the release from Chernobyl. The higher number is obviously worrying, says De Geer, although ongoing ground surveys are the only way to truly establish the public-health risk.

Stohl believes that the discrepancy between the team's results and those of the Japanese government can be partly explained by the larger data set used. Japanese estimates rely primarily on data from monitoring posts inside Japan ${ }^{3}$, which never recorded the large quantities of radioactivity that blew out over the Pacific Ocean, and eventually reached North America and Europe. "Taking account of the radiation that has drifted out to the Pacific is essential for getting a real picture of the size and character of the accident," says Tomoya Yamauchi, a radiation physicist at Kobe University who has been measuring radioisotope contamination in soil around Fukushima.

Stohl adds that he is sympathetic to the Japanese teams responsible for the official estimate. "They wanted to get something out quickly," he says. The differences between the two studies may seem large, notes Yukio Hayakawa, a volcanologist at Gunma University who has also modelled the accident, but uncertainties in the models mean that the estimates are actually quite similar.

The new analysis also claims that the spent fuel being stored in the unit 4 pool emitted copious quantities of caesium-137. Japanese officials have maintained that virtually no radioactivity leaked from the pool. Yet Stohl's model clearly shows that dousing the pool with water caused the plant's caesium-137 emissions to drop markedly (see 'Radiation crisis'). The finding implies that much of the fallout could have been prevented by flooding the pool earlier.

The Japanese authorities continue to maintain that the spent fuel was not a significant source of contamination, because the pool itself did not seem to suffer major damage. "I think the release from unit 4 is not important," says Masamichi Chino, a scientist with the Japanese Atomic Energy Authority in Ibaraki, who helped to develop the Japanese official estimate. But De Geer says the new analysis implicating the fuel pool "looks convincing".

The latest analysis also presents evidence that xenon-133 began to vent from Fukushima Daiichi immediately after the quake, and before the tsunami swamped the area.

\section{RADIATION CRISIS}

Modelling the first week of the Fukushima disaster reveals that huge bursts of radioisotopes poured from reactors and a spent-fuel storage pond.

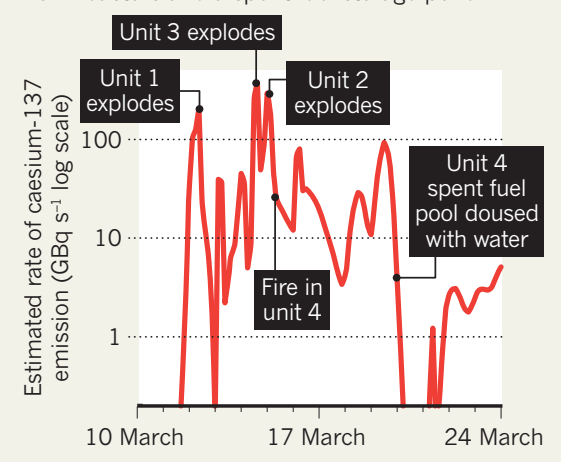

This implies that even without the devastating flood, the earthquake alone was sufficient to cause damage at the plant.

The Japanese government's report has already acknowledged that the shaking at Fukushima Daiichi exceeded the plant's design specifications. Anti-nuclear activists have long been concerned that the government has failed to adequately address geological hazards when licensing nuclear plants (see Nature 448, 392-393; 2007), and the whiff of xenon could prompt a major rethink of reactor safety assessments, says Yamauchi.

The model also shows that the accident could easily have had a much more devastating impact on the people of Tokyo. In the first days after the accident the wind was blowing out to sea, but on the afternoon of 14 March it turned back towards shore, bringing clouds of radioactive caesium-137 over a huge swathe of the country (see 'Radioisotope reconstruction'). Where precipitation fell, along the country's central mountain ranges and to the northwest of the plant, higher levels of radioactivity were later recorded in the soil; thankfully, the capital and other densely populated areas had dry weather. "There was a period when quite a high concentration went over Tokyo, but it didn't rain," says Stohl. "It could have been much worse." -

Additional reporting by David Cyranoski and Rina Nozawa.

1. Stohl, A. et al. Atmos. Chem. Phys. Discuss. 11, 28319-28394 (2011)

2. www.kantei.go.jp/foreign/kan/topics/201106/ iaea houkokusho e.html

3. Chino, M. et al. J. Nucl. Sci. Technol. 48, 1129-1134 (2011).

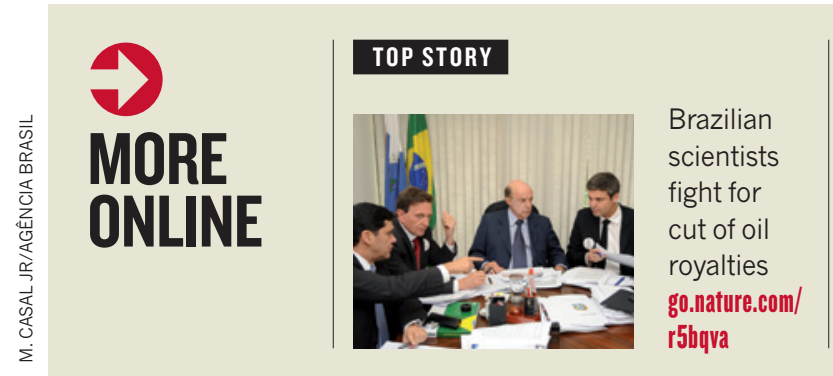

\section{OTHER NEWS}

- Finding puts brakes on faster-thanlight neutrinos go.nature.com/sitdhx - Mastodon fossil throws up questions over 'rapid' extinction go.nature.com/la71te

- California finalizes climate regulations go.nature.com/7bk8hb

\section{Q\&A}

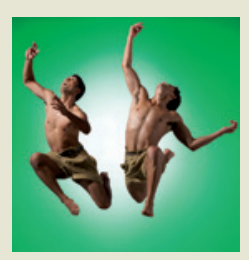

A leading dancer and a Cambridge scientist discuss their collaboration go.nature.com/scnplt 